that method was applicable. As the method has been widely adopted both in this country and abread I propose to describe some little improvements I have been able to make which allow the limits of its application to be considerably widened. Several correspondents wrote to me asking " what is anilin oil ?" as they had not been able to obtain it at the druggists, nor could they find the name in works on chemistry. In reply to these inquirers I have only to say that anilin oil is the same as anilin. It is the French huile d'anilin and the German anilinöl. It is, of course, not an oil at all, but is frequently termed such because of its oily consistence. When fresh it is almost colourless, but it turns yellow or brown with time. It should be kept in a glass-stoppered bottle and in a dark place.

In the paper referred to I described the method I then employed, using simply a 10 per cent. solution of cocaine hydrochlorate in a mixture of equal parts of anilin oil and rectified spirit. For ear work this proved highly satisfactory, but for operations involving deeper parts, such as excision of tonsils, the removal of bony spurs from the nasal septum, \&c., although much better than the simple aqueous solutions of cocaine it still did not completely annul the pain and, moreover, caused a burning sensation. The most obvious way to accomplish this end was to make the solution stronger, and this was what I did. To avoid the dangers of using strong solutions of cocaine, I mixed $\beta$-eucaine ${ }^{1}$ with the cocaine in the following way. Two solutions were made: (1) a 20 per cent. solution of cocaine hydrochlorate in rectified spirit; and (2) a 15 to 20 per cent. solution of eucaine in anilin oil. The latter is not a true solution, however, as eucaine is only soluble to about the extent of 10 per cent. in anilin oil ; a proportion of the eucaine, therefore, lies at the bottom of the bottle. Before use the bottle containing solution No. 2 is well shaken up and 10 minims (measured) are ponred out; to this are added 10 minims of No. 1 solution and the mixture becomes clear in a few seconds. This gives the following formula: cociane hydrochlorate 10 parts, $\beta$-eucaine 10 parts, anilin 50 parts, and rectified spirit 50 parts. Of course this solution may be kept in stock, but it turns brown very soon and arpears to a slight extent to lose its highly penetrating quality. I therefore keep the solutions separate until just before use, though perhaps the precaution is unnecessary. With this solution I have been able to dispense with all aqueous solutions of cocaine in ear and throat work.

The method of use is different according to the region in which the anæesthesia is desired. In the ear the method I formerly employed was to pour the solution into the meatus while the head was turned to one side. I frequently employ this method still, but another equally efficacious way was suggested to me by Dr. Arthur Hutchison-viz., to soak a small strip of ganze with the solution and to push it down the meatus through the speculum to the required depth. This method certainly diminishes the amount of cocaine and anilin oil absorbed.

In my previous communication I stated that the method was not suitable for throat and nose work on account of the burning pain which it temporarily caused. Further experience has led me to change my opinion in this respect, as I find that the disagreeableness of the burning sensation is fully compensated for by the much deeper anæsthesia obtained and the freedom from symptoms of cocaine intoxication. The method which I employ in throat and nose work is as follows. 10 minims (measured) of the eucaineanilin solution are poured out and 10 minims of the cocainespirit solution are mixed with them. The mixture, at first opaque, becomes clear and consists of a 10 per cent. solution of cocaine and 10 per cent. of eucaine. Under no circumstances do I use more than 20 minims of this solution-that is to say, 10 minims of anilin. That amount is quite sufficient for the painless excision of tonsils, removal of spurs on the septum, cauterising, and other operations. In applying the solution the anæsthetic effect appears to be considerably enhanced if it be rubbed gently over the part for a few seconds. This is done by saturating a small pledget of cotton-wool at the end of a probe with a few minims of the solation and rubbing it in. A period of at least seven minutes should then be allowed to elapse, at the end of which the anæsthesia will be found to be complete; much more so than that obtained by much larger quantities or stronger aqueous solutions of the anæsthetics. It should be

On the Use of Fucaine in Otolog 7 and Laryngology see a paper by Yearsley and Horne, Brit. Med. Jour., Jan. 16th, 1857 . added that if, after producing anæsthesia, chromic acid be used as an escharotic, the scab will be dark green in colour owing to the formation of an anilin dye. This produces no deleterious effect in the system and does not diminish the efficacy of the caustic.

In regard to the physiological effects of this method a few words are required. I have not bad any trouble myself with symptoms of intoxication, either by the anilin or by the cocaine. I have, however, heard of two cases in which a little trouble resulted. Of one of these I am nnable to give details as it was reported to me by a third person. It was a case evidently of cocaine intoxication and the patient recovered in the course of an hour or two. The second case occursed in a patient, aged six years. The solution was instilled into the meatus until the latter was full. In the course of an hour or so the patient's lips became blue and slight gastric catarrh occurred, but no other symptoms were present and the patient was well again in a few hours. As a matter of fact. beyond the peculiar blue colour of the lips there was nothing alarming to note. Excepting these cases, neither of which occurred in my own practice, I have not seen or heard of any trouble with the solution. On the other hand, I never have now any of those symptoms of cocaine intoxication with which rhinologists are so familiar when the aqueous solution is applied to the nasal mucous membrane, and which, though not usually alarming, are yet sufficient to prevent the carrying out of minor operations, much to the chagrin of the surgeon and the patient. Using the solutions in the manner described above excludes these extremely disagreeable symptoms.

A few words may be said in regard to the peculiar blue colour of the lips which sometimes occurs. Several of my patients have told me that an hour or two after the use of the solution their friends noticed this peculiar colour. No symptoms were present in any of the cases and the patients would not have known about it had their attention not been drawn to it by their friends. It always passes off in the course of a few hours and leaves no effects. Professor Stockman informs me that this is due to the transformation of oxyhæmoglobin into methæmoglobin. Its occurrence may be avoided if so desired by limiting the dose to 20 minims for adults or adolescents and corresponding doses for children. As regards children it must be remembered that they are said to stand cocaine badly. For my own part I have not seen any objectionable symptoms in children, but then I have always been careful about using cocaine in any form in these patients. Glasgow.

\section{TWO CASES ILLUSTRATING THE USE OF THE X RAYS IN SURGERY.}

BY G. P. NEWBOLT, F.R.C.S. ENG.,

HONORARY SURGEON TO THE ROYAL SOUTHERN HOSPITAL, IIVERPOOT; AND

C. THURSTAN HOLLAND, M.R.O.S. KNG., L.R.C.P. LOND.,

HONORARY MEDICAL OFFICER IN CHARGE OF THE X-RAY DEPARTMENT ROYAL SOUTHERN HOSPITAI, IIVERPOOL.

CASE 1.-The patient was a boy, aged 18 years, who was shot in the face. On August 28th whilst lying down another boy pointed a revolver into his face and it accidentally went off. The left eye being injured he was taken to the Liverpool Eye and Ear Infirmary where the eye was removed on the following day by the honorary surgeon, Mr. C. G. Lee. The bullet was not found in the eye, and on August 30 th an $\mathrm{x}$-ray examination was made by $\mathrm{Mr}$. Holland. The boy lying down on his left side, two wires were fixed at right angles to one another across the left side of the face, and the skiagram shown in Fig. 1 was obtained. The apparatus used was a 10-inch coil worked with accumulators and the exposure was 90 seconds. The wound of entrance was at the left side of the bridge of the nose, just internal to the angle of the eyelids. The bullet had passed through the left eye and across the superior maxilla, leaving small pieces of lead in different parts on its way along. The spot under which the bullet lay was, from the x-ray examination, given as follows: draw a line straight forward from the lower margin of the lobe of the left ear and measure one inch from 
the lobe along this line. From the sharpness and size of the boy, aged 16 years, who had when cleaning a window falles shadow it was estimated that the depth would not be more backwards into an area and been badly burt. When seen than about an inch beneath the skin.

On Sept. 4th Mr. Newbolt made a small incision in the cheek with this spot as its centre. Dissecting straight down through subcutaneous tissue and through the masseter some hours after the accident, the cut, \&c., having already been attended to, he was complaining of some difficulty in swallowing. As he was still in a very dazed condition it was FIG. 1.

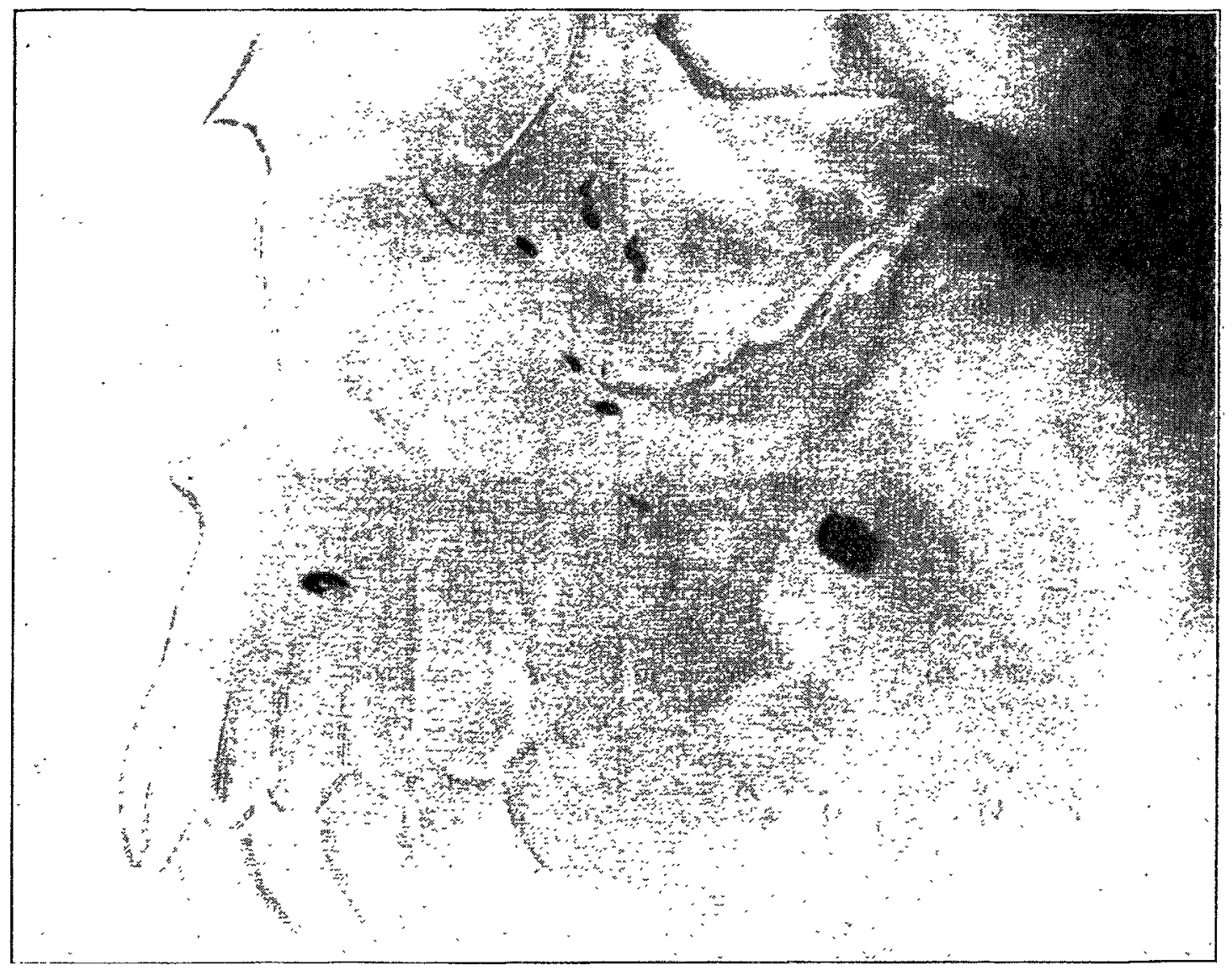

Reproduction of skiagram by Mr. C. Thurstan Holland. Shows bullet and scattered fragments in the face for two days

FIG. 2.

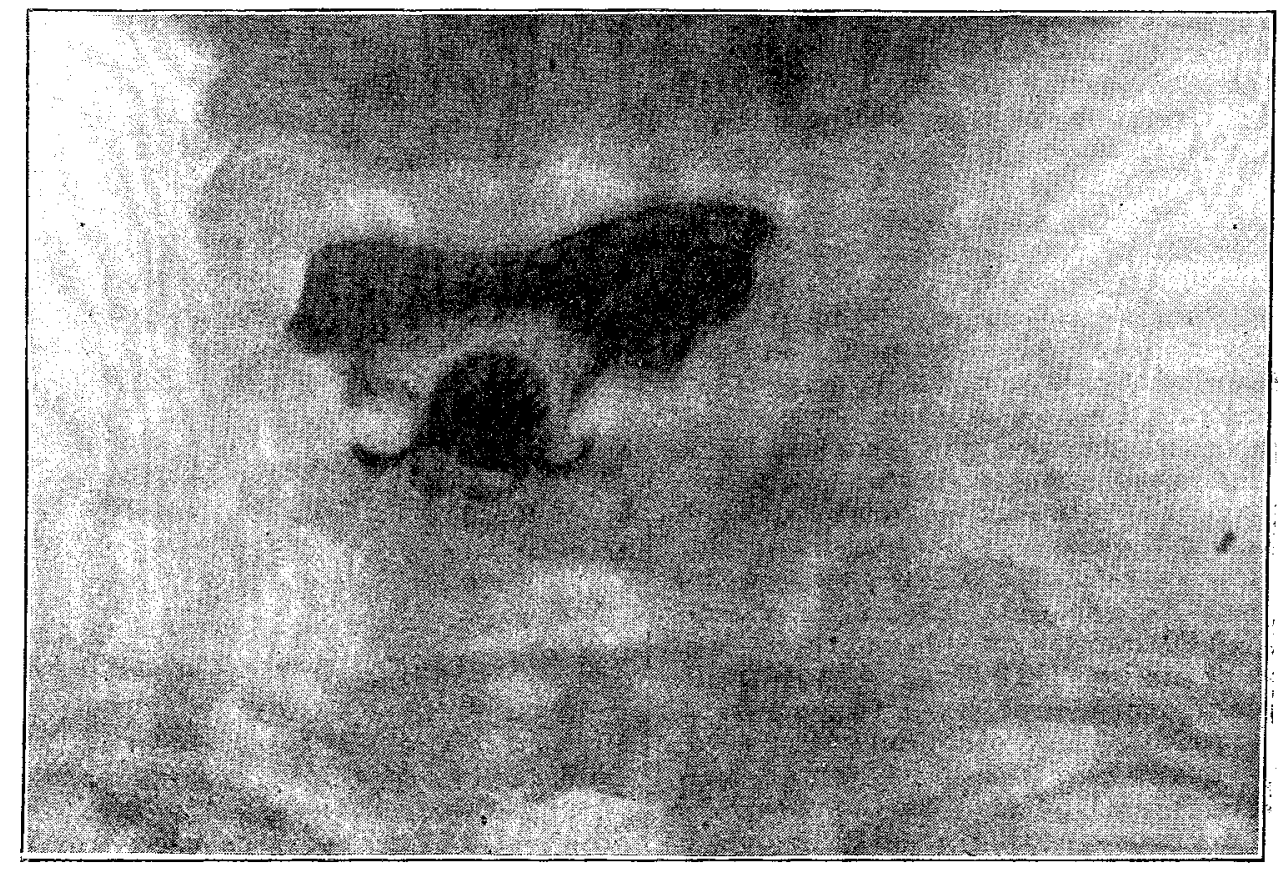

Reproduction of skiagram by Mr. C. Thurstan Holland. Shows vulcanite plate, with one tooth and books, in the cesophagus for six hours.

the bullet was found beneath this muscle, at about the depth from the skin of one inch. No difficulty occurred except that it was very firmly embedded and was not easy to dislodge. The wound healed by first intention and the boy made an uninterrupted recovery.

CaSi 2.-On July 27th Mr. Holland was sent for to see a noticed by his friends that a front upper false tooth on a small vulcanite plate with two hooks was missing from the month. This could not be found anywhere, so it was decided to examine the boy with the $x$ rays. On looking at him with the screen a foreign body resembling a tooth-plate could be easily seen fixed behind the larynx and it moved up and down 
during efforts at swallowing. The skiagram (Fig. 2) was taken with the same apparatus as in the preceding case and with an exposure of 60 seconds. The boy was then transferred to the Southern Hospital and there under an anæsthetic Mr. Newbolt could just reach the top of the foreign body through the mouth with his finger. Without any difficulty he then managed to catch hold of it with a pair of strong forceps and to remove it. The boy made an uninterrupted recovery.

Liverpool.

\section{Clinital a diptes:}

\section{MEDICAL, SURGICAL, OBSTETRICAL, AND THERAPEUTICAL.}

\section{NOTE ON A CASE OF MENINGO-MYELOCELE.}

By JaMes BURNeT, M.A., M.B., Ch.B. Edin.

ON Jan. 29th, 1901, at 11.45 P.M., I was called to attend a woman in labour. It was her third pregnancy. She had had twins, who died from "decline" six months after birth. Her next child, born four years ago, is alive and healthy. About 18 months ago she had an abortion at the third month and was ill for a long time afterwards. In May of last year I saw her and treated her for constipation and anæmia, with the result that she improved considerably in health. About the end of December she sent for me, as she began to complain of a severe pain in the suprapubic region and over the right iliac fossa. She looked then very much ran down. I prescribed for her, but she was unable to leave her bed much until labour set in on Jan. 29th. The presentation was a vertex one. There was some delay in the birth of the head, which was larger than the average. When born the child-a female-was asphyxiated, and gave evidence of convulsive twitchings in both arms and legs. Artificial respiration was performed, and the child soun revived and cried in a feeble manner. On examination I found a tumour situated in the lumbar region. It measured fully three and a half inches in length and two inches in breadth. It was sessile, and presented a wellmarked central cicatrix. There was talipes of both feet, with some rigidity of the knee joints. The knee reflexes appeared to be absent. The surface of the tumour was only partially covered by skin. The sac wall was very thin. The tumour was carefully dressed and protected from external pressure. In spite of our efforts, however, rupture was evident on the third day and the child died quietly on the morning of the seventh day, having previously refused the breast. Two days prior to death I observed considerable mottling of the face and trunk, with depression of the fontanelle. Examination of the heart was entirely negative. No postmortem examination was obtained, which I greatly regret.

The mother is a very neurotic woman, constipated and anæmic, always taking a very despondent view of life. No doubt these facts help to explain this early failure of development. I may add that the placenta and cord were perfectly normal.

Edinburgh.

\section{A CASE OF IRREDUOIBLE DORSAL DISLOCATION} OF THE PROXIMAL PHALANX OF THE INDEX FINGER.

By C. F. M. ALTHORP, M.B. LOND., SURGEON TO THE BRADFORD ROYAL INFIRMARY.

ON July 6th, 1900, a youth, aged 16 years, whilst at work in a warehouse in Bradford, fell off a ladder, alighting on the right hand and dislocating the proximal phalanx of the index finger. When seen at the infirmary soon after the accident the right index finger presented the following appearance. The base of the proximal phalanx formed a prominence on the dorsum of the hand, the head of the metacarpal bone projected into the palm, and the finger was shortened and there was limitation in movement. Attempts at reduction by manipulation were made by several of $\mathrm{my}$ colleagues as well as by myself, but without success. Gas, followed by ether was given and after the skin had been thoroughly cleansed an incision, an inch in length, was made over the radial side of the joint. The soft structures were drawn apart and the joint was freely exposed. A strong fibrous band, the glenoid ligament, was seen stretched over the head of the metacarpal bone, preventing reduction of the dislocation. The ligament was partly divided with the knife, and then with a blunt elevator I levered the stretched band over the articular end of the metacarpal bone. At once the dislocation was reduced. The wound was closed, without drainage, and when dressed a few days afterwards was found to be healed. Massage and passive movements were employed, the stiffness gradually disappearing.

In December, 1900, six months after the operation, the patient was shown to the members of the Bradford MedicoChirurgical Society. There were some thickening around the joint and slight limitation in extreme flexion. He had perfect use of the finger and could write as well as before the accident.

The case is of interest as illustrating the fact that in these dislocations (not only of the thumb but also of the fingers) it is the glenoid ligament which is the mechanical obstacle to reduction. By freely exposing the joint I was able to see the glenoid ligament stretched over the head of the metacarpal bone.

Bradford.

\section{DIABETES MELLITUS IN A OHILD, WITH OOMA.}

By J. G. McNadghton, M.D., M.R.C.P. Edin.

THE fact that diabetes mellitus in children, with rapid coma, is comparatively rare may make this case worthy of record.

I was called to see a girl, aged five years, on Jan. 21st, 1901, and obtained the following history. Wasting had been observed for only four weeks, and three weeks previously the mother had observed that the child was drinking large quantities of water. She would send her older sister for "drinks" during the night. At the same time she was passing more urine than usual. She complained of nothing else and played about as usual. No increase of appetite was observed. Three weeks before both ears discharged for one day, but there had been no discharge since. On examination on Jan. 21st the pulse was 116 and small ; the temperature was $97.6^{\circ} \mathrm{F}$. She was restless and difficult to rouse when spoken to. The skin was dry. The pupils were equal and there had been no twitching. She complained of no pain. The urine was straw-coloured and frothy, and on being tested it was found to contain sugar and albumin. The lungs and heart were normal.

On Jan. 22nd I was summoned at 7 A.M. The patient had vomited several times during the night. During the 24 bours she had passed over 20 ounces of urine. She was in great distress and complained of pain above the umbilicus. There was great dyspnoea, the respirations being 38 per minute. The lips, face generally, and limbs, especially the feet, were cyanosed; one tenth of a grain of codeia every three hours gave her some relief. The urine passed contained 6 per cent. of sugar and 3 per cent. of albumin. The patient was seen at 4 P.M.; there were even greater dyspncea and cyanosis, and she was gradually passing into a comatose state. The coma gradually deepened and she died at $3 \mathrm{~A} . \mathrm{M}$. on the next day.

The progress of the case was apparently very rapid, no urgent mischief beirg suspected till two days before death. The parents are intelligent people and careful of their children. The family history was not good. The mother has had five children and the eldest, an imbecile, died when about nine years of age. An aunt of the mother died from diabetes, and a sister of the father died from the same disease when over 50 years of age.

No examination of the body was allowed. It is possible that there may have been some change in the base of the brain, but one could get no history of irritation of cranial nerves, the only fact elicited being the discharge from the ears.

On Feb. 21st the mother of the child sickened with influenza. When seen for the first time on the 22nd the temperature was $100.4^{\circ}$ and the pulse was 98 . On the same evening she became acutely maniacal and she died 36 hours later in the same state. This note may be of interest, taken in connexion with Dr. Howship Dickinson's Baillie lecture in THE LANCE'T of Feb. 2nd, p. 299.

Turriff, N.B. 